\title{
Assertive Behaviors Among Nursing Staff in a Local Hospital in Iran
}

\author{
Mahdi Hadavi, ${ }^{1}$ and Mahdi Abdorrazagh Nejad ${ }^{2,}$ \\ ${ }^{1}$ College of Nursing and Midwifery, Birjand University of Medical Sciences, Birjand, Iran \\ ${ }^{2}$ Instructor, Faculty of Birjand University Medical Sciences, Birjand, Iran \\ "Corresponding author: Mahdi Abdorrazagh Nejad, Instructor, Faculty of Birjand University Medical Sciences, Birjand, Iran. Tel: +98-9153620130, E-mail: \\ mahdiabn40@yahoo.com
}

Received 2018 January 15; Revised 2018 March 17; Accepted 2018 April 20.

\begin{abstract}
Background and Objectives: As key members of healthcare teams, nurses need to establish communications with other healthcare providers, patients, and family members. Communication has three main types, namely passive, aggressive, and assertive. The most effective type of communication is the assertive type. Assertiveness is defined as the abilities to say no, express desires and negative/positive feelings, and start, continue, and finish a conversation. Assertiveness has many benefits for both nurses and patients. Yet, there are limited studies on assertiveness among Iranian hospital nurses. This study aimed to evaluate assertive behaviors among nurses in Qaen, an eastern city in Iran.

Methods: This cross-sectional descriptive-analytical study was conducted on all 160 nurses, auxiliary nurses, and anesthesia and operating room technicians who were working at Shoahday-e Qaen hospital, Qaen, Iran, in summer 2017. A demographic questionnaire and the valid and reliable Gambrill-Richey assertion inventory were employed for data collection. The SPSS for Windows program (v. 21.0) was used to analyze the data by running the Chi-square test.

Results: In total, 141 participants completely filled out and returned their questionnaires. They were mostly female (67.4\%) and married (82.3\%). The mean of their age was $31.49 \pm 7.3$ with a range of $18-52$. Only $21.3 \%$ of them were assertive, while the remaining $78.7 \%$ were either unassertive (31.2\%), anxious performer (32.6\%), or indifferent (14.9\%).

Conclusions: The hospital nursing staff has limited assertiveness. Therefore, educational programs are needed to promote their communication skills and assertiveness. Improvement of nurses' awareness and knowledge of communication skills and assertiveness can improve nurse-patient relationships, care quality, and patient outcomes.
\end{abstract}

Keywords: Assertiveness, Communication Skills, Nursing

\section{Background}

Effective communication between nurses and patients is a critical factor behind quality care delivery and a key component of sound nursing practice. It helps nurses identify patients' needs and take appropriate actions for their fulfillment (1). The nurses' competence in establishing effective communication with patients improves their self-confidence, demonstrates their professionalism, and earns others' respect and gratitude (1). Moreover, effective communication enables nurses to accurately diagnose patients' problems $(2,3)$, develop quality care plans, and establish professional relationships with other healthcare providers (2). Yet, a study on 1216 patients showed that $17 \%$ of them were dissatisfied with healthcare providers' communication abilities (4).

Communication has three main types, namely passive, aggressive, and assertive. The most effective type of communication is the assertive type (5). Assertiveness is de- fined as the ability to equally value one's and others' beliefs and ideas. In other words, it is the ability to fulfill one's needs, defend one's rights, and express one's feelings, beliefs, and thoughts while simultaneously considering and respecting others' rights (6). Another definition for assertiveness is the abilities to say no, express desires and negative/positive feelings, and start, continue, and finish a conversation (7). It happens when a person is able to express his/her ideas in delicate situations (8). Assertiveness is an intrapersonal behavior developed in social interactions that helps individuals express their rights, feelings, and thoughts in acceptable ways (8).

Assertiveness has different outcomes. It helps people show positive social behaviors, have appropriate social interactions with others, and improve their problemsolving ability and self-awareness (9). Sound assertive behaviors enable people to establish closer relationships and express their needs and thoughts without feeling anxious or harming others (5). In healthcare settings, assertive- 
ness strengthens interprofessional relationships, prevents workplace violence (10), reduces occupational stress, minimizes negligence, and improves nurses' leadership ability, job satisfaction, professional autonomy, and professional efficacy (6). Besides, it can bring nurses professional dignity, enable them to solve their professional problems and prevent them from making inaccurate judgments (11). Assertiveness is also directly correlated with nurses' caring skills (4). Because of its numerous outcomes, assertiveness is considered a valuable skill in nursing (6).

Despite the importance of assertiveness to sound nursing practice and quality care delivery, previous studies show that nurses have limited assertiveness. For instance, a study reported that $60 \%$ of nursing students suffered from some levels of unassertiveness, which had negatively affected their learning and efficacy in $40 \%$ of cases (12). Another study into students' mental health reported limited assertiveness as one of the most important problems among university students (13).

To the best of our knowledge, limited studies have been conducted so far on nurses' assertiveness in eastern and southeastern parts of Iran. Therefore, the present study was designed and undertaken to evaluate assertive behaviors among nurses in Qaen, an eastern city in Iran.

\section{Methods}

This cross-sectional descriptive-analytical study was conducted on all 160 nurses, auxiliary nurses, and anesthesia and operating room technicians who were working at Shoahday-e Qaen hospital, Qaen, Iran in summer 2017. The participants were recruited through the census method. Inclusion criteria were a hospital work experience of one year or more and an associate or higher degree in nursing, anesthesia, or operating room, or an auxiliary nursing diploma. Exclusion criterion was voluntary withdrawal from the study.

A demographic questionnaire and the Gambrill-Richey assertion inventory $(14,15)$ were employed for data collection. The items of the demographic questionnaire were age, gender, nursing degree, marital status, work experience, and organizational position. The Assertion Inventory contained 40 items. The participants were asked to answer the inventory in two rounds. In the first round, they rated their discomfort and anxiety for each item on a five-point scale from "None" to "Very much." In the second round, they were asked to determine their probable behavioral response in actual situations. The total scores of the first and the second rounds represented the two dimensions of assertiveness, namely discomfort and response probability. The scores of these two dimensions were used to determine whether a respondent was indifferent, unassertive, anxious performer, or assertive (Table 1). An earlier study on 40 guidance-school female students reported that the 26-day test-retest correlation coefficients of the discomfort and the response probability dimensions of the assertion inventory were 0.82 and 0.67 , respectively (16).

$\begin{aligned} & \text { Table 1. Assertion Inventory Score Interpretation Based on the Scores of Its Two Di- } \\
& \text { mensions }\end{aligned}$
\begin{tabular}{lcc} 
Discomfort & \multicolumn{1}{c}{ Response Probability } & \\
& $\leq \mathbf{1 0 4}$ & $\geq \mathbf{1 0 5}$ \\
\hline$\geq \mathbf{9 6}$ & Anxious performer & Unassertive \\
$\leq \mathbf{9 5}$ & Assertive & Indifferent \\
\hline
\end{tabular}

\subsection{Ethical Considerations}

This study obtained ethical approval from the ethics committee of Birjand University of Medical Sciences, Birjand, Iran (approval code: IR.BUMS.REC.1396.71). Participants were informed about the study aim and the confidential handling of their information.

Study data were analyzed using the SPSS for Windows program (v. 21.0). The Chi-square test was performed at a significance level of less than 0.05 to examine the relationship of assertiveness with demographic characteristics.

\section{Results}

From 160 participants, 141 completely filled out and returned their questionnaires. The mean of their age was $31.49 \pm 7.3$ with a range of $18-52$, while the mean of their work experience was $24.8 \pm 7.04$ with a range of 1 - 29 . Most participants were female (95 cases, 67.4\%) and married (116 cases, $82.3 \%$ ), and had bachelor's degree in nursing (82 cases, $58.2 \%$ ).

As Table 2 shows, $31.2 \%$ of the participants were unassertive and only $21.3 \%$ of them were assertive. Their assertiveness had no significant relationships with their gender, marital status, nursing degree, organizational position, and participation in social skills courses $(\mathrm{P}>0.05$; Table 3).

\begin{tabular}{ll}
\hline Table 2. Assertiveness Status Among Study Participants & \\
\hline Assertiveness Status & No. (\%) \\
\hline Assertive & $30(21.3)$ \\
Anxious performer & $46(32.6)$ \\
\hline Indifferent & $21(14.9)$ \\
Unassertive & $44(31.2)$ \\
\hline Total & $141(100)$ \\
\hline
\end{tabular}




\begin{tabular}{|c|c|c|c|c|c|}
\hline \multirow[t]{2}{*}{ Characteristics } & \multicolumn{4}{|c|}{ Assertiveness Status; No. (\%) } & \multirow[t]{2}{*}{ P Value } \\
\hline & Assertive & Anxious Performer & Indifferent & Unassertive & \\
\hline Gender & & & & & 0.44 \\
\hline Male & $9(19.6)$ & $17(37.0)$ & $9(19.6)$ & $11(23.9)$ & \\
\hline Female & $21(22.1)$ & $29(30.5)$ & $12(12.6)$ & $33(34.7)$ & \\
\hline Marital status & & & & & 0.10 \\
\hline Married & $23(19.8)$ & $41(35.3)$ & $14(12.1)$ & $38(32.8)$ & \\
\hline Single & $7(28.0)$ & $5(20.0)$ & $7(28.0)$ & $6(24.0)$ & \\
\hline Nursing degree & & & & & 0.45 \\
\hline Auxiliary nurse & $6(26.1)$ & $10(43.5)$ & $4(17.4)$ & $3(13.0)$ & \\
\hline Bachelor of Science & $17(21.5)$ & $24(30.4)$ & $9(11.4)$ & $29(36.7)$ & \\
\hline Operating room associate diploma & $5(27.8)$ & $4(22.2)$ & $3(16.7)$ & $6(33.3)$ & \\
\hline Anesthesia associate diploma & $0(0)$ & $6(40.0)$ & $4(26.7)$ & $5(33.3)$ & \\
\hline Master of Sciences & $2(33.3)$ & $2(33.3)$ & $1(16.7)$ & $1(16.7)$ & \\
\hline Organizational position & & & & & 0.75 \\
\hline Matron or supervisor & $1(33.3)$ & $0(0)$ & $1(33.3)$ & $1(33.3)$ & \\
\hline Head nurse & $1(11.1)$ & $3(33.3)$ & $2(22.2)$ & $3(33.3)$ & \\
\hline Staff nurse & $23(19.8)$ & $39(33.6)$ & $16(13.8)$ & $38(32.8)$ & \\
\hline Ward clerk & $5(38.5)$ & $4(30.8)$ & $2(15.4)$ & $2(15.4)$ & \\
\hline Participation in social skills courses & & & & & 0.95 \\
\hline Yes & $6(20.7)$ & $10(34.5)$ & $5(17.2)$ & $8(27.6)$ & \\
\hline No & $24(21.4)$ & $36(32.1)$ & $16(14.3)$ & $36(32.1)$ & \\
\hline
\end{tabular}

\section{Discussion}

This study assessed hospital nursing staff's assertiveness and its relationship with their demographic characteristics. The findings showed that most participants had limited assertiveness (78.7\%), i.e. were either anxious performer (32.6\%), indifferent $(14.9 \%)$ or unassertive (31.2\%). Similarly, an earlier study reported that $66 \%$ of nurse entrepreneurs were unassertive, $47 \%$ were anxious performer, and only $24 \%$ of them had assertive behaviors (17).

Our findings also indicated that only $11.1 \%$ of head nurses and $19.8 \%$ of nurses had assertive behaviors. Similarly, two earlier studies reported that nurses had limited assertiveness $(10,18)$. These findings highlight the importance of developing strategies and programs for promoting nurses' assertiveness. We also found that $21.3 \%$ of our participants were assertive and $31.2 \%$ were unassertive. These values in a previous study were $23.7 \%$ and $76.3 \%$, respectively. That study also reported that greater assertiveness was associated with lower likelihood of suffering from violence (19). Another study on 274 bachelor's nursing students in Turkey also reported that more than half of them had limited assertiveness in clinical settings (20). Moreover, a study on Iranian nursing and midwifery students found that $59.60 \%$ of them had moderate assertiveness, $22.20 \%$ had high assertiveness, and $18.21 \%$ had low assertiveness (6). In line with our findings, a study on internship nursing students found that the prevalence of high, moderate, and low assertiveness among them was $20 \%$, $68 \%$, and $12 \%$, respectively (21). Another study also showed limited assertiveness among nursing students (22). Such low assertiveness among nurses and nursing students may be due to the unawareness of their legal rights, their low self-confidence, physicians' dominance in healthcare settings, and managers' reluctance to engage nurses in decision-making and policy-making and give them greater professional autonomy.

Our findings also indicated no significant difference between male and female participants respecting their assertiveness score, though female participants obtained slightly higher assertiveness scores than their male counterparts. This finding may be attributable to the greater number of females in the present study (67.4\%) and their ability to communicate more easily with each other. In 
line with our findings, several earlier studies reported no significant relationship between gender and assertiveness (22-24). However, a study showed greater assertiveness among female nursing and midwifery students (6), while another study reported significantly greater assertiveness among male students (25). These discrepancies among studies can be due to the differences in their samples, designs, and data collection instruments. Moreover, gender socialization can be an explanation for the difference between men and women in terms of their assertiveness. In addition, men are engaged in social activities more than women are and hence, they are usually more assertive while women are more passive (22). However, the insignificant relationship between gender and assertiveness in the present study may be due to the obedience of both male and female nurses to physicians.

We also found that single participants were relatively more assertive than their married counterparts were, even though the difference was not statistically significant. The greater assertiveness of single individuals may be attributable to their lower familial commitment and lower concern over employment loss. Similarly, an earlier study found that single midwives were more assertive than their married counterparts were (26).

\subsection{Conclusion}

This study concludes that the hospital-nursing staff has limited assertiveness. Therefore, nursing managers need to implement educational programs in order to promote their assertiveness and self-confidence and thereby, improve care quality and patient satisfaction. Assertiveness can be a critical and life-saving skill in critical situations and can improve patients' confidence in nurses' abilities and competence. Given the potential effects of the immediate sociocultural context on assertiveness, the present study can be replicated in other contexts and on larger samples of hospital staff. Moreover, investigating the effects of interventions such as participatory management model, assertiveness training, and self-awareness and communication improvement strategies on assertiveness can be other areas for further research.

\section{Acknowledgments}

This article was part of a research project that had been approved and supported by Birjand University of Medical Sciences, Birjand, Iran (with the approval code of IR.BUMS.REC.1396.71 and the tracking number of 4375). Hereby, we thank the research administration of the university, the faculties of Birjand Nursing and Midwifery Faculty, and the nursing staff of Shohaday-e Qaen hospital for their help and support throughout the study.

\section{References}

1. Ghaffarifar S, Ghofranipour F, Ahmadi F, Khoshbaten M. [Why educators should apply theories and models of health education and health promotion to teach communication skills to nursing and medical students]. Nurs Midwifery Stud. 2015;4(4). Persian.

2. Khatib Zanjani N, Moharreri M. [Assessing the nurses' knowledge and awareness of effective verbal communication skills]. Interdiscip J Virtual Learn Med Sci. 2012;3(1). Persian.

3. de Rezende Rde C, de Oliveira RM, de Araujo ST, Guimaraes TC, do Espirito Santo FH, Porto IS. Body language in health care: a contribution to nursing communication. Rev Bras Enferm. 2015;68(3):430-6. 490-6. doi: 10.1590/0034-7167.2015680316i. [PubMed: 26312521].

4. Montini T, Noble AA, Stelfox HT. Content analysis of patient complaints. Int J Qual Health Care. 2008;20(6):412-20. doi: 10.1093/intqhc/mzn041. [PubMed: 18801751].

5. Taghavi Larijani T, Mardani Hmouleh M, Rezaei N, Ghadiriyan F, Rashidi A. Relationship between assertiveness and critical thinking in nursing students. J Nurs Educ. 2014;3(1):32-40.

6. Baghani R, keyghobadi F, Tabaraei Y. [Factors affecting nursing and midwifery students'decisiveness in 2013]. Q J Sabzevar Univ Med Sci. 2014;20(5):674-9. Persian.

7. Lazarus AA. On assertive behavior: A brief note. Behav Ther 1973;4(5):697-9. doi: 10.1016/s0005-7894(73)80161-3.

8. Unal S. Evaluating the effect of self-awareness and communication techniques on nurses' assertiveness and self-esteem. Contemp Nurse. 2012;43(1):90-8. doi: 10.5172/conu.2012.43.1.90. [PubMed: 23343237].

9. Barim Nejad L, Mardani Hamoole M, Saed Fatemi N, Mostaghasi M. [The survey of communication bethween nursing assertivness and reporting of nursing fault]. Q Sic Tebb Kar. 2013;5(2):60-5. Persian.

10. Karakas SA, Okanli A. The Effect of Assertiveness Training on the Mobbing That Nurses Experience. Workplace Health Saf. 2015;63(10):446-51. doi: 10.1177/2165079915591708. [PubMed: 26242741].

11. Yin YC. The assertive nursing administrator. Hu Li Za Zhi J Nurs. 2011;58(3):17-20.

12. Goldsmith JB, McFall RM. Development and evaluation of an interpersonal skill-training program for psychiatric inpatients. J Abnorm Psychol.1975;84(1):51-8. doi: 10.1037/h0076264. [PubMed: 1110273].

13. Noorbala AA, Bagheri Yazdi SA, Yasamy MT, Mohammad K. Mental health survey of the adult population in Iran. Br J Psychiatry. 2004;184:70-3. doi:10.1192/bjp.184.1.70. [PubMed: 14702230].

14. Gambrill ED, Richey CA. An assertion inventory for use in assessment and research. Behav Ther. 1975;6(4):550-61. doi: 10.1016/s0005 7894(75)80013-x.

15. Sacherman C. Using the Gambrill-Richey assertion inventory to personalize assertion training.J Specialists Group Work. 2016;4(1):9-15. doi 10.1080/15496295.1979.11728550.

16. Amali khamenei SH. [The survey and comparison between the effect of assertivness method and assertivness method joint with recognition reform on several adolescent with social anxiety]. Inst Psychiatry Tehran.1994;1(4):18-29. Persian.

17. Sankelo M, Akerblad L. Nurse entrepreneurs' attitudes to management, their adoption of the manager's role and managerial assertiveness. J Nurs Manag. 2008;16(7):829-36. doi: 10.1111/j.1365 2834.2008.00917.x. [PubMed: 19017245].

18. Suzuki E, Saito M, Tagaya A, Mihara R, Maruyama A, Azuma T, et al. Relationship between assertiveness and burnout among nurse managers. Jpn J Nurs Sci. 2009;6(2):71-81. doi: 10.1111/j.1742-7924.2009.00124.x. [PubMed: 20021576].

19. Okanli A, Karakas SA, Ozkan H. The relationship between mobbing and assertiveness in nurses. HealthMED. 2011;5(3):609-15. 
20. Unal S, Hisar F, Gorgulu U. Assertiveness levels of nursing students who experience verbal violence during practical training. Contemp Nurse. 2012;42(1):11-9. doi: 10.5172/conu.2012.42.1.11. [PubMed 23050567].

21. Rasouli N, Ghamari Zare Z. [Level of assertiveness and its barriers among nursing internship students]. J Health Care. 2015;17(2):100-7. Persian.

22. Seyedfatemi N, Moshirabadi Z, Borimnejad L, Haghani H. Relationship between problem solving and assertiveness skills among nursing students. J Hayat. 2013;19(3):70-81.

23. Taghavi Larijani T, Rezayat F, Seyedfatemi N, Mehran A. [The effect of the assertiveness training program on nursing students' assertive- ness skills]. J Nurs Educ. 2013;1(2):42-52. Persian.

24. Borimnejad L, Mardani Hmouleh M, Seyed Fatemi N, Mostaghaci M. [Relationship between assertiveness and reporting of job errors among nurses]. Occup Med QJ. 2013;5(2):60-5. Persian.

25. Dinçyurek S, Çağlar M, Silman F. Determination of the locus of control and level of assertiveness of the students studying in the TRNC in terms of different variables. Procedia Soc Behav Sci. 2009;1(1):12-22. doi: 10.1016/j.sbspro.2009.01.007.

26. Yurtsal ZB, Ozdemir L. Assertiveness and problem solving in midwives. Iran J Nurs Midwifery Res. 2015;20(6):647-54. doi: 10.4103/17359066.170016. [PubMed: 26793247]. [PubMed Central: PMC4700681]. 